\title{
SIMULATION AND EXPERIMENTAL STUDIES OF A 2.45GHZ MAGNETRON SOURCE FOR AN SRF CAVITY WITH FIELD AMPLITUDE AND PHASE CONTROLS*
}

\author{
H. Wang\#, T. Plawski, R.A. Rimmer \\ Thomas Jefferson Lab, Newport News, VA 23606, USA \\ M. Neubauer, A. Dudas \\ Muons, Inc. 552 N. Batavia Ave. Batavia, IL 60510 USA
}

\begin{abstract}
Phase lock to an SRF cavity by using injection signal through output waveguide of a magnetron has been demonstrated [1, 3]. Amplitude control using magnetic field trimming and anode voltage modulation has been studied using MATLAB/Simulink simulations [2]. Based on these, we are planning to use an FPGA based digital LLRF system, which allows applying various types of control algorithms in order to achieve the required accelerating field stability. Since the $1497 \mathrm{MHz}$ magnetron is still in the design stage, the proof of principle measurements of a commercial 2450 $\mathrm{MHz}$ magnetron are carried out to characterize the anode I-V curve, output power (the tube electronic efficiency), frequency dependence on the anode current (frequency pushing) and the Rieke diagram (frequency pulling by the reactive load). Based on early Simulink simulation, experimental data and extension of the Adler equation governing injection phase stability by Chen's model, the specification of the new LLRF control chassis for both 2450 and $1497 \mathrm{MHz}$ systems are presented in this paper.
\end{abstract}

\section{INTRODUCTION}

As a drop-in replacement for the CEBAF $13 \mathrm{~kW}$ CW klystron system, a $1497 \mathrm{MHz}$, CW type high-efficiency magnetron using injection phase lock with amplitude variation is under development. Magnetrons used in industrial and medical accelerators normally have 85-95\% electronic efficiency, much higher than typical klystrons within the same perveances [2]. Current CEBAF klystrons only have efficiency of $35-55 \%$. The ultimate goal of using magnetrons instead of klystrons for the CEBAF and future JLEIC machines is for both capital and operation cost reduction. The capital cost of a klystron or solid state amplifier is in the range \$5-25 per output Watt depending on the power rate and production quantity. However a magnetron, which can be both operated in CW or pulse modes if it is designed and controlled properly, can be operated with both high gain and high efficiency. Its production cost can be as low as $\$ 0.1$ per output Watt like a typical oven magnetron. The performance of an injection locked CW magnetron to phase control a SRF cavity was first demonstrated at JLab in conjunction with Lancaster

To re-establish the JLab magnetron test stand and to further investigate phase and amplitude control accuracy of an SRF cavity by a dedicated digital Low Level RF (LLRF) controller, a new $2.45 \mathrm{GHz}$ magnetron system TMA12 including WR340 waveguide components was purchased

\footnotetext{
* Authored by Jefferson Science Associates, LLC under U.S. DOE Contract No. DE-AC05-06OR23177 and NP STTR Grant DE-SC0013203.

\# haipeng@jlab.org
}

University, UK, in 2010 [1, 3] with accuracy of $0.95^{\circ} \mathrm{rms}$ at $-23.5 \mathrm{~dB}$ injection signal.

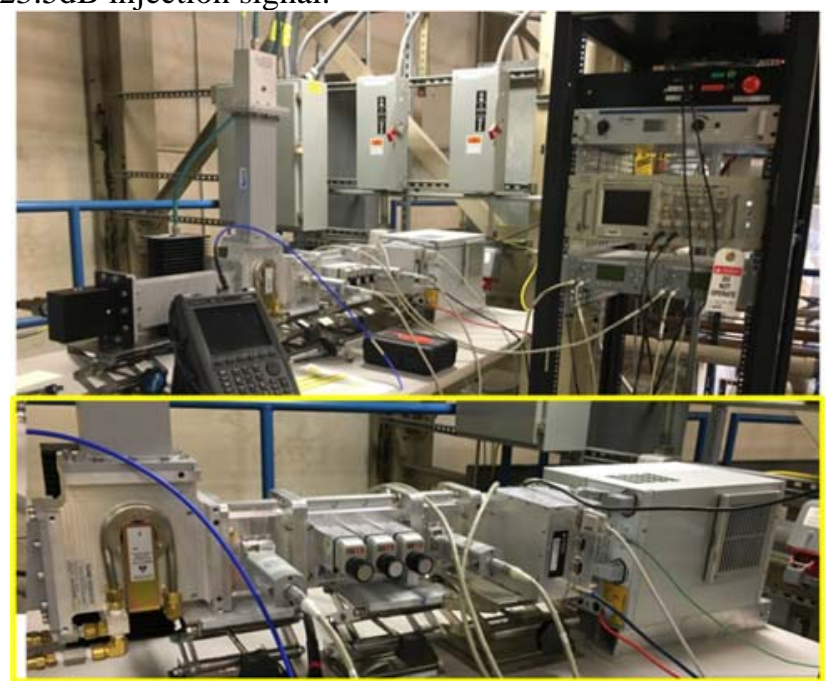

Figure 1: $2.45 \mathrm{GHz}, 1.2 \mathrm{~kW}$ magnetron test stand (top) and the setup (bottom) to a matched load.

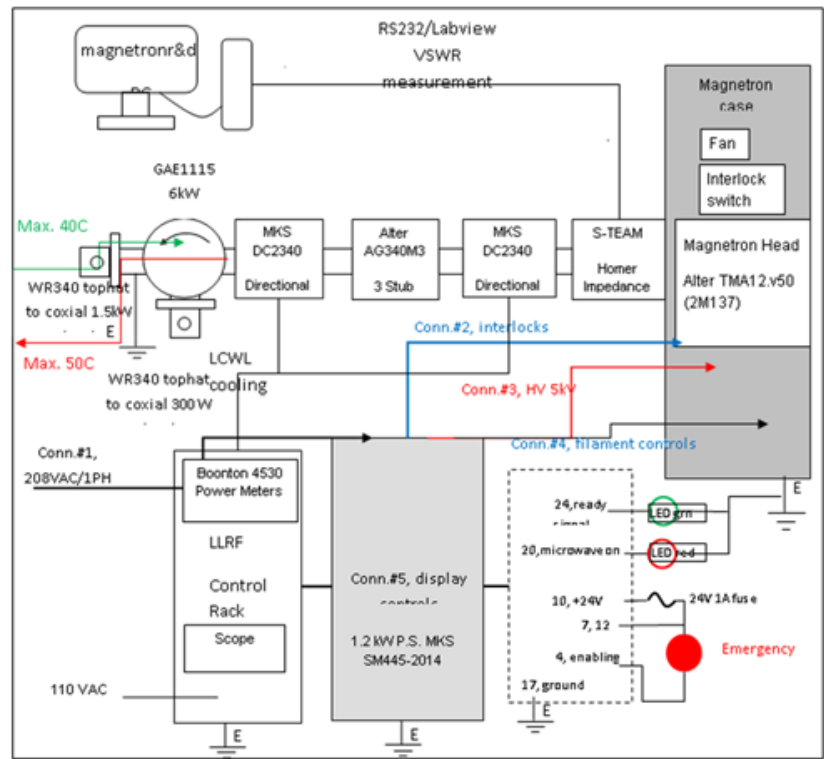

Figure 2: Circuit diagram of Alter magnetron test to a matched load for Rieke diagram measurement.

from a company, MKS for Alter Products. It is intended to duplicate the National Electronics 2M137IL magnetron head used in 2010 [1, 3]. A 3-stub tuner to vary the magnetron output impedance and an S-Team Homer in-line impedance analyser of WR340 waveguide type were also used for the Rieke diagram measurement. 
The initial test was carried out into a matched load only. However two WR340 isolators purchased from Richardson Electronics did not meet isolation specification due to a mismatch of the built-in water load. Instead a WR340 circulator from Gerling was used with an adaptor to an $\mathrm{N}$ type high power load. The characterization of the magnetron input/output parameters can be measured without too much reflected power to the magnetron head that could trip the magnetron body interlock thermostat.

\section{PRELIMINARY TEST RESULTS TO A MATCHED LOAD}

The first measurement of the power spectrum around $2.45 \mathrm{GHz}$ as a function of the fraction of maximum output power, roughly as the reference level in \%, was done by changing the Pulse Width Modulation (PWM) of the switching power supply on the front knob. As shown in Figure 3, a $90-100 \%$ of output power level gives more monotonic spectrum which is a suitable working point for the frequency lock.

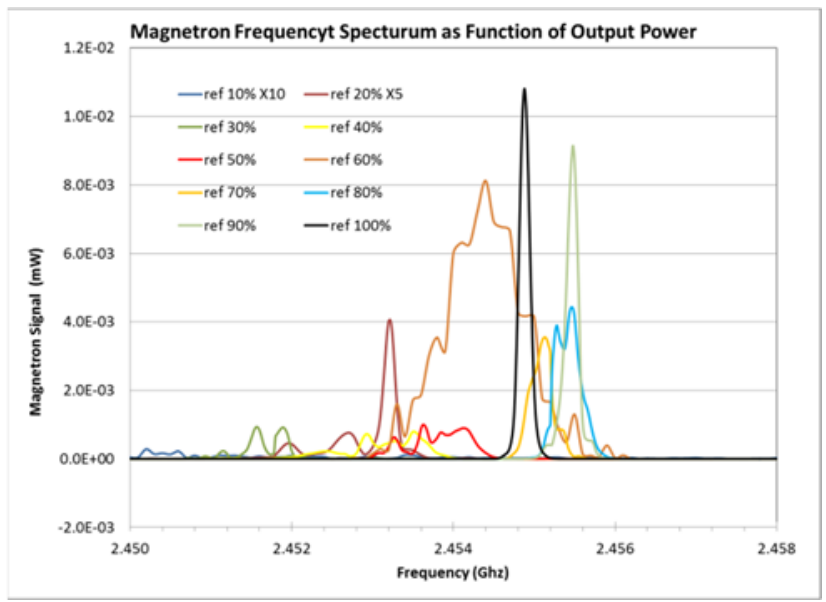

Figure 3: MKS TMA12 magnetron power spectrum measurement to a matched load through a WR340 Coupler.

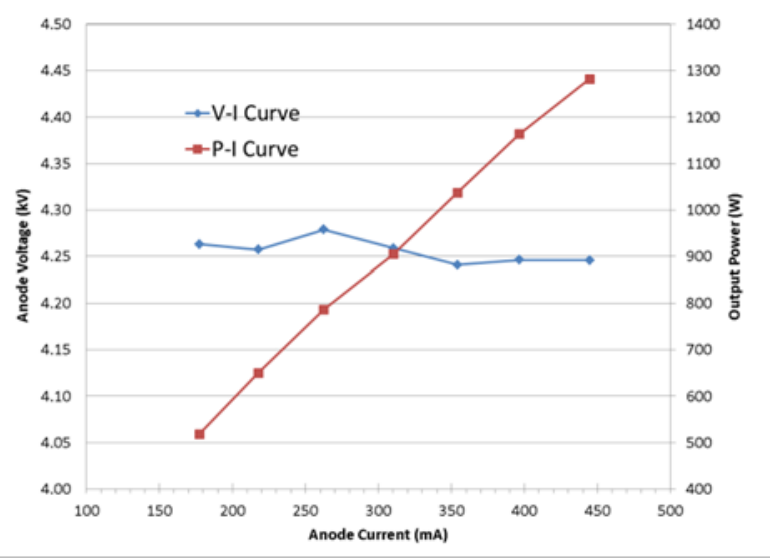

Figure 4: V-I and P-I curves of TMA12 magnetron.

A nearly flat anode V-I curve was observed for output power from $518 \mathrm{~W}$ to $1282 \mathrm{~W}$ as shown in Figure 4, indicating a constant voltage mode of power supply operation and a nearly linear response of P-I curve.
The magnetron operates at nearly $70 \%$ of electronic efficiency as shown in Figure 5, close to its design parameter of this type of magnetron head. The frequency pushing by the anode current is about $17 \mathrm{MHz}$ in this power range as shown in Figure 6, much larger than a -30dB injection signal can be locked bandwidth which has been studied in Ref [4]. Then a frequency lock for the amplitude control will be designed by using both trimming up the magnetic field [2] and tuning a reactive load [4].

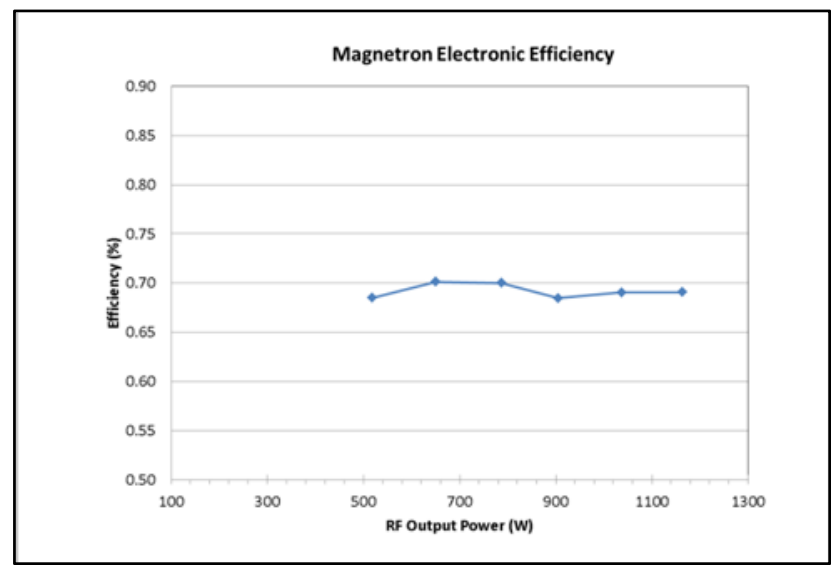

Figure 5: Electronic efficiency in operation parameter range.

The frequency pulling effect by the VSWR change from 1.2 to 1.7 is about $4 \mathrm{MHz}$ from the measurement data in Figure 7. More parameter scans are going to be done in order to obtain a more comprehensive data tables for generating the constant power and frequency contour lines in the Rieke diagram.

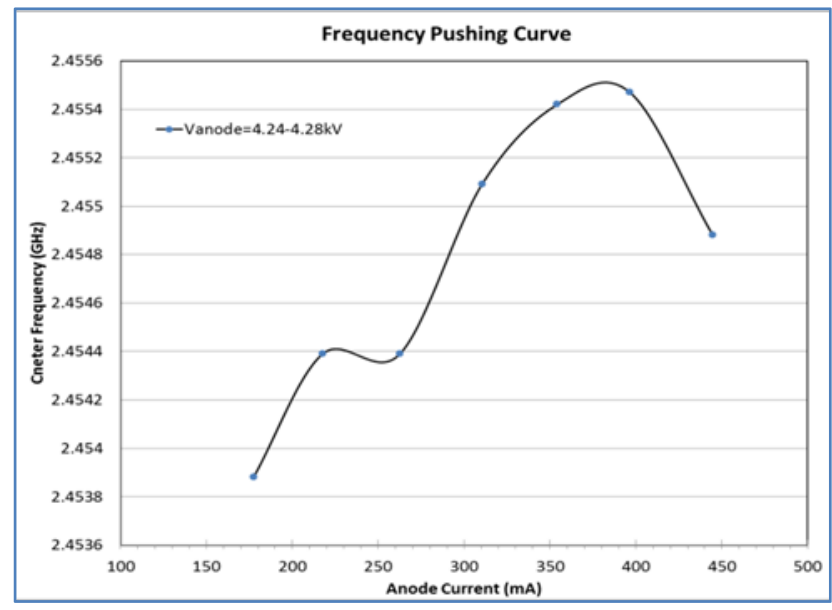

Figure 6: Frequency push curve by anode current change.

High frequency noise on the anode current was directly measured on the switching power supply current monitor. A FFT spectrum indicates that the noise peak is at $84 \mathrm{kHz}$, second harmonic of the switching frequency at $42 \mathrm{kHz}$. This noise figure could finally affect the phase lock performance $[1,3,4]$, so an alternative push-pull type DC power supply will be evaluated for the next phase of tests to lock RF and SRF cavities. 


\section{WORK PLAN IN THE NEXT TWO YEARS}

Under the funded SBIR Phase II and the CRADA between JLab and Muons Inc, we are going to develop two LLRF controllers, one for $2450 \mathrm{MHz}$ magnetron system and one for $1497 \mathrm{MHz}$. Both of them will be designed and built based on the architecture of the existing JLab digital LLRF system [5]. We are going to complete the prototype $1497 \mathrm{MHz}, 13 \mathrm{~kW}$ $\mathrm{CW}$ magnetron and using the test results from the $2450 \mathrm{MHz}$ system in the first year to develop the second controller for the high power tests of the prototype $1497 \mathrm{MHz}$ magnetron in the second year.

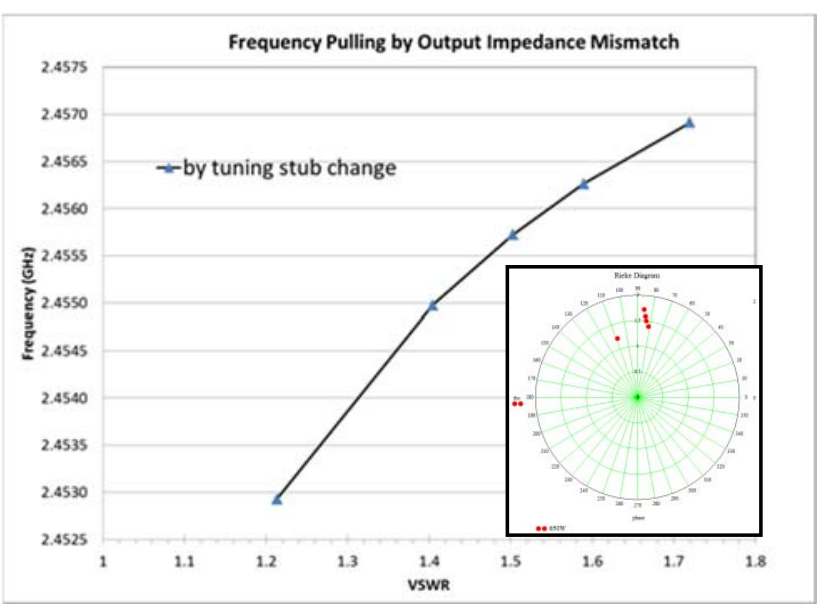

Figure 7: Preliminary frequency pulling curve measured by one stub change only on the output waveguide.

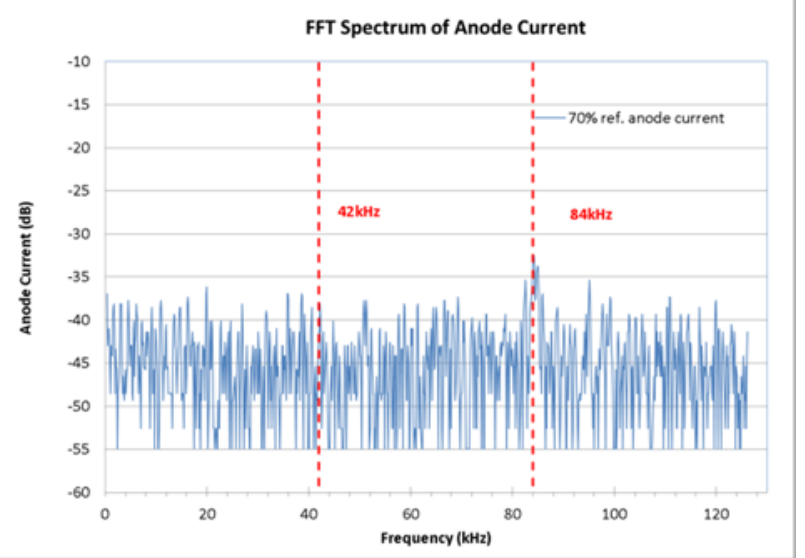

Figure 8: FFT spectrum measured directly by TDS2014B scope from magnetron power supply anode current monitor.

\section{LLRF CONTROL SPECIFICATION}

The preliminary top level specification for the LLRF controller is based on the document [6] and Simulink simulation results [2], the carrier frequency of either $2450 \mathrm{MHz}$ or $1497 \mathrm{MHz}$ can be easily changed via the Local Oscillator (LO). In Table 1, we list the high level parameters for the application of CEBAF SRF cavities and the magnetron test stands that are under the development.

Table 1: Top level specification for magnetron controllers

\begin{tabular}{|c|c|}
\hline Cavity RF field regulation & Response $(</>1$ sec $)$ \\
\hline Phase stability (corr.) rms. & $0.24^{\circ} /$ inf. \\
\hline $\begin{array}{l}\text { Phase stability (un-corr.) } \\
\text { rms. }\end{array}$ & $0.5^{\circ} / 3.0^{\circ}$ \\
\hline Amplitude (corr.) rms. & $2.2 \times 10^{-5} / \mathrm{NA}$ \\
\hline Amplitude (un-corr.) rms. & $4.5 \times 10^{-5} / \mathrm{NA}$ \\
\hline $\begin{array}{l}\text { Set point resolution } \\
\text { amp/phase }\end{array}$ & $0.1 \% / 0.1^{\circ}$ \\
\hline Nearby cavity mode rejection & digital \\
\hline PID gains $\left(\mathrm{K}_{\mathrm{P}}, \mathrm{K}_{\mathrm{I}}, \mathrm{K}_{\mathrm{D}}\right)$ & $\begin{array}{c}\text { Programmable } \\
\text { independent to set } \\
\text { point }\end{array}$ \\
\hline $\begin{array}{l}\text { Latency excluding } \\
\text { cable, magnetron, waveguide }\end{array}$ & $<600 \mathrm{~ns}$ \\
\hline $\begin{array}{l}\text { Modes of operation and loop } \\
\text { switch }\end{array}$ & $\begin{array}{c}\text { Pulsed / CW / Open / } \\
\text { Close } \\
\end{array}$ \\
\hline $\begin{array}{l}\text { External input sync }(>10 \mathrm{kHz} \\
\text { BW) }\end{array}$ & $\begin{array}{l}\text { For fast feedback and } \\
\text { feed forward } \\
\end{array}$ \\
\hline Carrier frequency & 1497 / $2450 \mathrm{MHz}$ \\
\hline Bandwidth (-3dB) & $1 \mathrm{MHz}$ \\
\hline Clock reference frequency & $10 \mathrm{MHz}$ \\
\hline IF frequency (TBD) & 70MHz@0dBm SMA \\
\hline LO frequency & Carrier-IF @TDB \\
\hline Cavity Q Q load & $0.8-3.2 \times 10^{7}$ \\
\hline RF Power from magnetron & $\begin{array}{c}\text { 13kW (1dB comp. } \\
\text { 14kW satu. 20dB } \\
\text { dyna.) }\end{array}$ \\
\hline $\begin{array}{l}\text { Cavity microphonic max } \\
\text { detune }\end{array}$ & $4 \mathrm{~Hz} 1 \sigma, 24 \mathrm{~Hz} 6 \sigma$ \\
\hline $\begin{array}{l}\text { Lorentz Force Detune LDF } \\
\max \end{array}$ & $2 \mathrm{~Hz} /(\mathrm{MV} / \mathrm{m})^{2}$ \\
\hline LLRF Control System & Same as C100's \\
\hline Diagnostic / Buffers & $\mathrm{P}_{\mathrm{f}} / \mathrm{P}_{\mathrm{r}} / \mathrm{P}_{\mathrm{t}} / \mathrm{I} \& \mathrm{Q} /$ errors \\
\hline Pulse mode for bunch trains & $<1 \mathrm{kHz}, 1-100 \%$ Duty \\
\hline Feed forward \& adaptive & For pulsed mode only \\
\hline $\begin{array}{l}\text { SEL mode for LDF \& auto- } \\
\text { track }\end{array}$ & auto-tune \\
\hline High Power Interface & Modify from C100's \\
\hline Cathode voltage & 6 Analog outputs \\
\hline Magnet trim coil current & $(100 \mathrm{kHz}-10$ to $+10 \mathrm{~V})$ \\
\hline Anode voltage & Variable gains \\
\hline Anode current & 2 ADCs 16 bit \\
\hline Magnetron RF injection & $1 \mathrm{MHz}-10$ to $+10 \mathrm{~V}$ \\
\hline Control and interlock & Same as C100's \\
\hline Resonance control & $\begin{array}{c}\text { Stepper motor and } \\
\text { Piezo }\end{array}$ \\
\hline \multirow[t]{2}{*}{ Interlocks } & BL and WG Vacuums \\
\hline & Windows arc and temp \\
\hline Cavity heaters & 8, 40-80W each \\
\hline
\end{tabular}

\section{REFERENCES}

[1] A. C. Dexter, G. Burt, R. G. Carter, I. Tahir, H. Wang, K. Davis and R. Rimmer, PRST-AB, 14, 032001 (2011)

[2] H. Wang etc., Proceedings of IPAC 2015, Richmond, VA, USA. WEPWI028

[3] H. Wang, etc., Proceedings of IPAC 2010, THPEB067

[4] I. Tahir, PhD thesis, Lancaster University UK, July 2009 
[5] C. Hovater et al, "A Digital Self Excited Loop for Accelerating Cavity Field Control,” PAC'07, Albuquerque USA, June 2007, WEPMS065, p. 2490

[6] H. Dong, etc., Performance and Technical Requirements for the CEBAF Energy Upgrade Low Level RF System, JLab Internal Report, 2006 